\title{
Nitrous oxide as an effective AFM tip functionalization: a comparative study
}

\author{
Taras Chutora ${ }^{1}$, Bruno de la Torre ${ }^{* 1,2}$, Pingo Mutombo ${ }^{2}$, Jack Hellerstedt ${ }^{2}$, \\ Jaromír Kopeček ${ }^{2}$, Pavel Jelínek ${ }^{1,2}$ and Martin Švec ${ }^{* 1,2}$
}

\section{Full Research Paper}

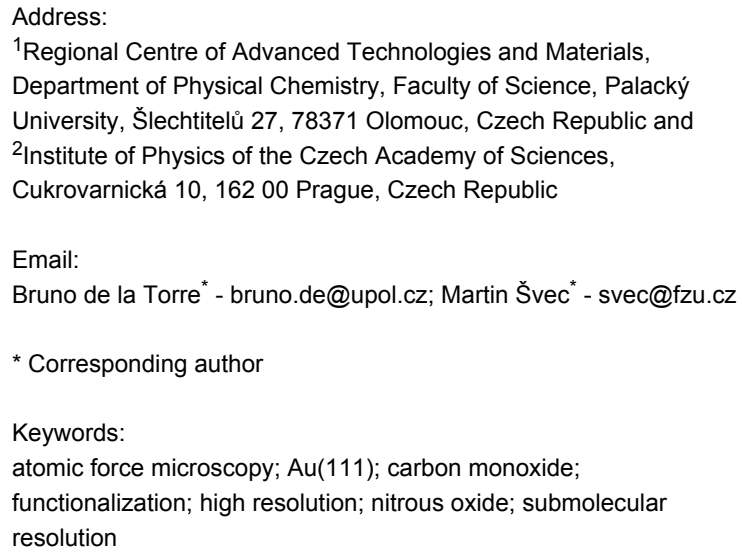

${ }^{1}$ Regional Centre of Advanced Technologies and Materials, Department of Physical Chemistry, Faculty of Science, Palacký University, Šlechtitelů 27, 78371 Olomouc, Czech Republic and ${ }^{2}$ Institute of Physics of the Czech Academy of Sciences, Cukrovarnická 10, 16200 Prague, Czech Republic

Email:

Bruno de la Torre* - bruno.de@upol.cz; Martin Švec ${ }^{*}$ - svec@fzu.cz

* Corresponding author

Keywords:

atomic force microscopy; $\mathrm{Au}(111)$; carbon monoxide; functionalization; high resolution; nitrous oxide; submolecular resolution

Beilstein J. Nanotechnol. 2019, 10, 315-321. doi:10.3762/bjnano. 10.30

Received: 24 October 2018

Accepted: 07 January 2019

Published: 30 January 2019

This article is part of the thematic issue "Advanced atomic force microscopy II".

Guest Editor: T. Glatzel

(C) 2019 Chutora et al.; licensee Beilstein-Institut.

License and terms: see end of document.

\begin{abstract}
We investigate the possibility of functionalizing Au tips by $\mathrm{N}_{2} \mathrm{O}$ molecules deposited on a $\mathrm{Au}(111)$ surface and their further use for imaging with submolecular resolution. First, we characterize the adsorption of the $\mathrm{N}_{2} \mathrm{O}$ species on $\mathrm{Au}(111)$ by means of atomic force microscopy with CO-functionalized tips and density functional theory (DFT) simulations. Subsequently we devise a method of attaching a single $\mathrm{N}_{2} \mathrm{O}$ to a metal tip apex and benchmark its high-resolution imaging and spectroscopic capabilities using FePc molecules. Our results demonstrate the feasibility of high-resolution imaging. However, we find an inherent asymmetry of the $\mathrm{N}_{2} \mathrm{O}$ probe-particle adsorption on the tip apex, in contrast to a $\mathrm{CO}$ tip reference. These findings are consistent with DFT calculations of the $\mathrm{N}_{2} \mathrm{O}$ - and $\mathrm{CO}$ tip apexes.
\end{abstract}

\section{Introduction}

Frequency-modulated atomic force microscopy (AFM) has become the tool of choice for the characterization of molecules on the atomic scale. Functionalization of a metallic tip apex with a single carbon monoxide molecule $(\mathrm{CO})$ was the key to achieve submolecular resolution for the first time, on a pentacene molecule [1]. This milestone initiated a vigorous development of the technique that now serves a variety of purposes. For example, it can identify molecular structures of natural and pure compounds [2-5], determine the bond order in conjugated systems [6], visualize intramolecular charge distributions [7-9], image three-dimensional molecular structures [10-12], discern complex molecular mixtures [13,14], resolve the intermediate states of chemical reactions [15-19] or discriminate the spin state of single molecules [20]. 
In most of these cases, the functionalized tip is routinely obtained by picking up a single $\mathrm{CO}$ molecule from the substrate. Applying an analogous approach, atomically sharp metal apexes can be also decorated either by different molecular species such as $\mathrm{C}_{60}$ [21], naphthalenetetracarboxylic diimide (NTCDI) [22], $\mathrm{NO}$ [23] or single atoms such as $\mathrm{Xe}$ [24,25], $\mathrm{Br}$ [24], $\mathrm{Kr}$ [24], O [26], and $\mathrm{Cl}[1,27]$. Such tip terminations have proved to be fairly stable and therefore capable of achieving submolecular resolution. The characteristics of each type of tip termination, such as chemical structure or internal charge distribution, are extremely important for the AFM contrast, distortions in the molecule images, and spatial resolution $[8,27,28]$. The tipterminating particle also significantly affects the spectroscopy measurements, i.e., the interaction energy toward different atomic species in force spectroscopy, the contact potential difference in Kelvin probe force microscopy (KPFM) [9,29] and vibrational levels of inelastic tunneling spectroscopy (IETS) [30,31]. A particular termination of the tip may be bound to certain types of substrates, and better suited for a limited range of investigated objects, such as molecules with specific functional groups or atomic impurities with characteristic charge distribution. Therefore it is of utmost importance to search for new potentially practical molecules for tip functionalization and describe their unique properties.

Here we present a process in which $\mathrm{N}_{2} \mathrm{O}$ was deposited on a $\mathrm{Au}(111)$ substrate and characterized. Subsequently we functionalized the Au tip with $\mathrm{N}_{2} \mathrm{O}$ and benchmarked its capabilities by imaging a FePc molecule and performing force-distance spectroscopy. The data is compared to equivalent measurements done with a Au tip functionalized with $\mathrm{CO}$.

\section{Results and Discussion}

A clean $\mathrm{Au}(111)$ surface was inserted into the microscope head and cooled to $5 \mathrm{~K}$ before exposing it to $\mathrm{N}_{2} \mathrm{O}$ gas. Figure $1 \mathrm{a}$ shows a characteristic constant-current image of the $\mathrm{N}_{2} \mathrm{O}$ / $\mathrm{Au}(111)$ system, revealing the formation of small 2D clusters, preferentially located at the kinks of the characteristic herringbone structure. Their variable size is typically a few nanometers in diameter. The estimated average apparent height of the cluster formations was $70 \mathrm{pm}$.

After the $\mathrm{N}_{2} \mathrm{O}$ cluster formation, the metallic tip (pre-treated by a gentle indentation into the substrate) was functionalized by an impurity CO molecule, which significantly improved the resolution in both STM and AFM. We performed high-resolution AFM/STM measurements on various clusters (comparable to the inset of Figure 1a), which revealed elongated structures; we attribute these to individual flat-lying $\mathrm{N}_{2} \mathrm{O}$ molecules. In a cluster, typically composed of 5-25 molecules, the $\mathrm{N}_{2} \mathrm{O}$ molecules have a preferential short-range arrangement of rotation-

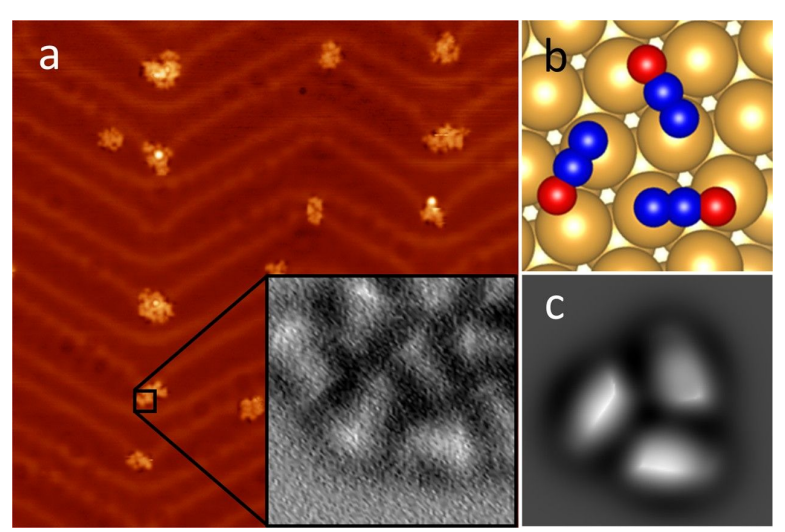

Figure 1: Adsorption of $\mathrm{N}_{2} \mathrm{O}$ molecules on the $\mathrm{Au}(111)$ substrate. (a) Overview STM image (100 mV, $\left.10 \mathrm{pA}, 50 \times 50 \mathrm{~nm}^{2}\right)$ of a sample after $\mathrm{N}_{2} \mathrm{O}$ deposition. Inset: a close-up AFM image $\left(1.5 \times 1.5 \mathrm{~nm}^{2}\right)$ of the $\mathrm{N}_{2} \mathrm{O}$ cluster adsorbed on the herringbone elbow, scanned with a CO-functionalized tip. (b) Top view of the calculated adsorption geometry of a $\mathrm{N}_{2} \mathrm{O}$ trimer. (c) Simulated AFM image $\left(1.5 \times 1.5 \mathrm{~nm}^{2}\right)$ of a $\mathrm{N}_{2} \mathrm{O}$ trimer on $\mathrm{Au}$ (111) using the probe-particle model [32].

ally symmetrical trimers, with intermolecular distances of about $4.3 \AA$. A DFT calculation of a single $\mathrm{N}_{2} \mathrm{O}$ molecule on the surface confirms that its adsorption configuration on $\mathrm{Au}(111)$ is primarily driven by a non-covalent dispersion interaction and prefers to orient its longer axis parallel to the $[2 \overline{1} \overline{1}]$ axis of the surface. The vertical distance between the single molecule and the surface was estimated to be $3.5 \AA$. Based on this finding, we construct an atomic model of the three flat-lying $\mathrm{N}_{2} \mathrm{O}$ molecules on $\mathrm{Au}(111)$ and optimize it with total-energy DFT calculations. We find that the trimer is stabilized by electrostatic interactions between the $\mathrm{N}$ and $\mathrm{O}$ atoms of adjacent $\mathrm{N}_{2} \mathrm{O}$ molecules, due to their slightly different polarization. The calculations reveal that the preferred orientation of the $\mathrm{N}_{2} \mathrm{O}$ molecules in the clusters is with the $\mathrm{O}$ atoms outward (Figure 1b), being $17 \mathrm{meV}$ more stable than the opposite arrangement.

Using the optimized geometry of the cluster obtained from DFT calculations, as an input for the probe-particle model [32], we simulated the AFM images to determine the atomic contrast of the $\mathrm{N}_{2} \mathrm{O}$ trimer (Figure 1c). Note that the probe-particle was mimicking a $\mathrm{CO}$ molecule. We found good agreement between theory and experiment.

We were able to functionalize the tip with a $\mathrm{N}_{2} \mathrm{O}$ molecule. In various attempts to adsorb $\mathrm{N}_{2} \mathrm{O}$ onto the tip, we discovered that by intentionally reducing the bias to $50-100 \mathrm{mV}$ for several seconds in constant-current mode while scanning an area containing a cluster of $\mathrm{N}_{2} \mathrm{O}$ molecules, a sudden improvement of the resolution occurred (as shown in Figure 2a). This event is characteristic for the tip picking up a molecule from the surface $[33,34]$ and therefore can be attributed to a transfer of a $\mathrm{N}_{2} \mathrm{O}$ 

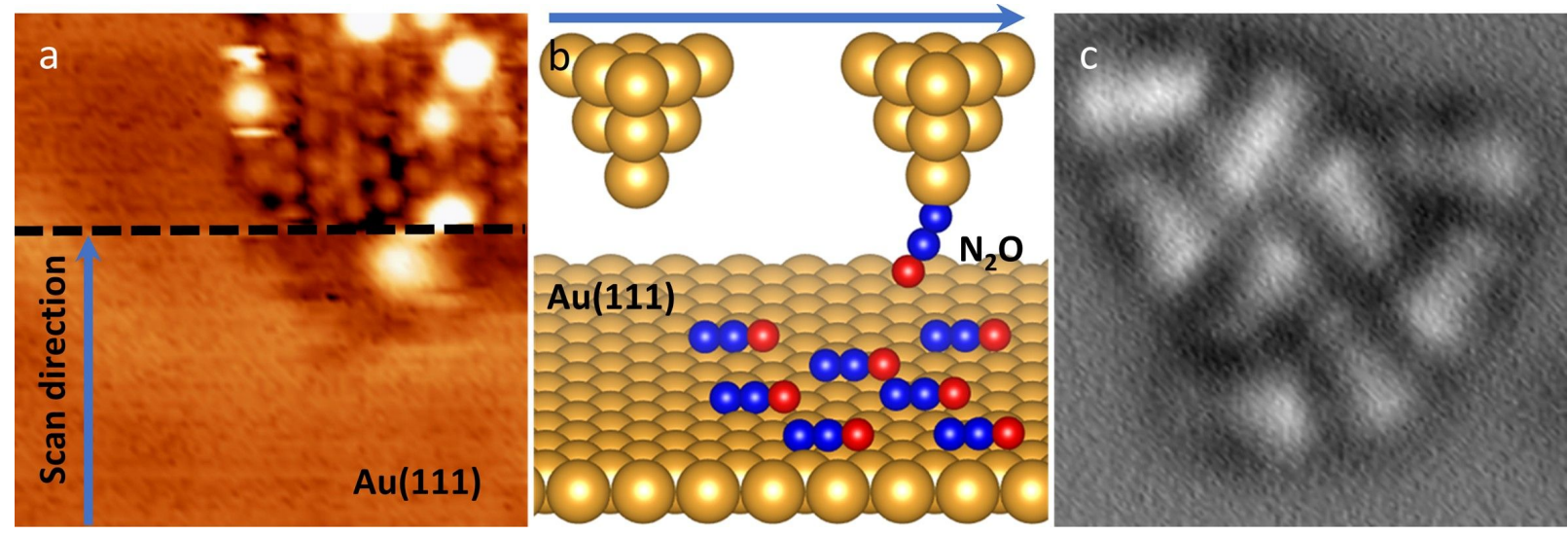

Figure 2: Tip functionalization with a $\mathrm{N}_{2} \mathrm{O}$ molecule. (a) STM image $\left(100 \mathrm{mV}, 10 \mathrm{pA}, 6 \times 6 \mathrm{~nm}^{2}\right)$ demonstrating a spontaneous enhancement of the resolution while scanning over the $\mathrm{N}_{2} \mathrm{O}$-covered surface. (b) Schematic representation of the functionalization process (blue arrow indicates the scan direction). (c) Constant-height AFM image $\left(2 \times 2 \mathrm{~nm}^{2}\right)$ of a single $\mathrm{N}_{2} \mathrm{O}$ cluster obtained with a $\mathrm{N}_{2} \mathrm{O}$-functionalized tip.

molecule from the surface to the tip apex, as schematically shown in Figure 2b. We propose that the $\mathrm{N}_{2} \mathrm{O}$ molecule is attached to the tip apex through the terminal $\mathrm{N}$ (Figure 2b), which has a more reactive character compared to the $\mathrm{O}$ atom [35]. In this manner, the $\mathrm{O}$ atom would be responsible for the majority of interaction with the substrate.

After functionalization of the tip apex with a single $\mathrm{N}_{2} \mathrm{O}$ molecule, we obtained a high-resolution AFM image of the $\mathrm{N}_{2} \mathrm{O}$ cluster (Figure 2c). The $\mathrm{N}_{2} \mathrm{O}$ tip exhibits good stability during the measurement, allowing us to scan at smaller tip-sample separations and to enter the Pauli repulsion regime. The AFM image of the $\mathrm{N}_{2} \mathrm{O}$ cluster Figure $2 \mathrm{c}$ shows a remarkably similar resolution to the images acquired with a CO-decorated tip.

In order to understand the chemical behavior of the $\mathrm{N}_{2} \mathrm{O}$ tips and compare them to the CO tips, we carried out DFT calculations of their electrostatic potential and total densities (see Methods for more detail). Figure 3 shows the calculated electrostatic potential (ESP) map for $\mathrm{CO}$ and $\mathrm{N}_{2} \mathrm{O}$ attached to a $\mathrm{Au}$ pyramid, projected onto isosurfaces of their respective total electron densities (cut at $0.03 \mathrm{e} / \mathrm{A}^{3}$ ). The spatial ESP variation is an important factor for the determination of the molecular reactivity and can be interpreted as the static distribution of the charge around the molecule [36].

The ESP maps of the $\mathrm{CO}$ and the $\mathrm{N}_{2} \mathrm{O}$ molecule attached to the gold tip (Figure 3) possess some similar characteristics. Both molecules have similar variation of the potential along the probe molecule, i.e., the regions with negative values around the $\mathrm{C}-\mathrm{O}$ and $\mathrm{N}-\mathrm{O}$ bonds (electron-rich area, colored in blue) and regions with positive values at the terminal $\mathrm{O}$ atoms (electron-poor area, colored in red). This indicates that the $\mathrm{N}_{2} \mathrm{O}$ tip is
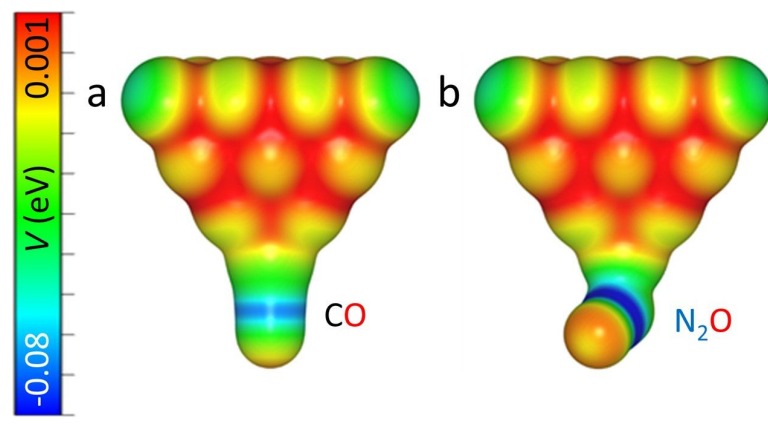

Figure 3: Comparison of the calculated electrostatic potential projections of the $\mathrm{CO}(\mathrm{a})$ and $\mathrm{N}_{2} \mathrm{O}$ (b) tips obtained through DFT calculations.

very similar to the CO tip in terms of spatial charge distribution. However, the Hirschfeld analysis [37] of atomic charge at the $\mathrm{O}$ apex atom gives $-0.077 e$ for the $\mathrm{N}_{2} \mathrm{O}$ tip, compared to $-0.055 e$ for the $\mathrm{CO}$ tip. This can result in a larger electrostatic interaction of the $\mathrm{N}_{2} \mathrm{O}$ probe with a charged atom or molecule. Also, the geometry of the probe particles on the tip is remarkably different. The $\mathrm{CO}$ molecule is attached to the Au pyramid almost perfectly on its axis, whereas $\mathrm{N}_{2} \mathrm{O}$ is bent strongly. The bent adsorption configuration of the $\mathrm{N}_{2} \mathrm{O}$ molecule is caused by electrostatic interactions between the molecule and the Au tip, which arise from the mutual dipole-dipole interaction. Furthermore, the calculated adsorption energies of the two molecules on the tip differ as well. We have found a value of $-0.840 \mathrm{eV}$ for $\mathrm{CO}$, compared to $-0.156 \mathrm{eV}$ for $\mathrm{N}_{2} \mathrm{O}$. So while a $\mathrm{N}_{2} \mathrm{O}$ tip might still provide the resolution and sensitivity needed for submolecular imaging, an asymmetry is expected in the images made by the $\mathrm{N}_{2} \mathrm{O}$ tips and interaction forces may have a larger electrostatic contribution. 
To benchmark the performance of the $\mathrm{N}_{2} \mathrm{O}$-decorated tip experimentally, we used it to obtain high-resolution STM/AFM images of a single FePc molecule, which is suitable as a standard due to its planar shape and the flat adsorption geometry on $\mathrm{Au}(111)$ [31]. A submonolayer coverage of FePc molecules was deposited on $\mathrm{Au}(111)$ at room temperature, and the $\mathrm{FePc} /$ $\mathrm{Au}(111)$ surface was subsequently cooled down in the microscope and exposed to $\mathrm{N}_{2} \mathrm{O}$. Figure 4 shows an overview STM image of the obtained sample, where the FePc molecules predominantly occupy the fcc-stacked Au regions and the kinks of the $\mathrm{Au}(111)$ herringbone reconstruction. The $\mathrm{N}_{2} \mathrm{O}$ species adsorbs planarly as in the previous experiment, clustering in the vicinity of single FePc molecules. To functionalize the tip with a single $\mathrm{N}_{2} \mathrm{O}$ molecule on such a sample we used the procedure described above. We scan a small region around a single $\mathrm{FePc}$ molecule that is surrounded by $\mathrm{N}_{2} \mathrm{O}$ molecules, at a setpoint of $50 \mathrm{mV}$ and $20 \mathrm{pA}$ until the characteristic change in the contrast, which is associated with the functionalization, occurs (inset of Figure 4).

With this functionalized tip, we performed imaging with submolecular resolution on one of the FePc molecules, surrounded by the $\mathrm{N}_{2} \mathrm{O}$ species. Figure 5a shows the corresponding set of constant-height STM/AFM maps, along with the reference data acquired with a CO tip on a single FePc molecule on $\mathrm{Au}(111)$.

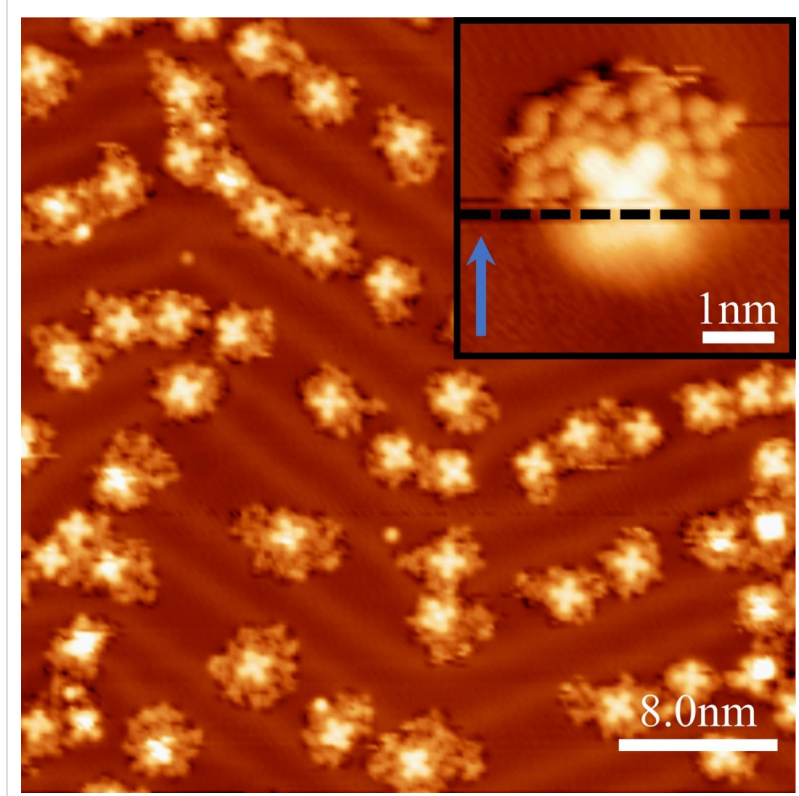

Figure 4: Constant-current STM images of the co-adsorption of FePc and $\mathrm{N}_{2} \mathrm{O}$ molecules on a $\mathrm{Au}(111)$ surface $(200 \mathrm{mV}, 20 \mathrm{pA}$,

$40 \times 40 \mathrm{~nm}^{2}$ ), imaged with a $\mathrm{N}_{2} \mathrm{O}$-functionalized tip. Inset: STM image $\left(50 \mathrm{mV}, 20 \mathrm{pA}, 5 \times 5 \mathrm{~nm}^{2}\right.$ ) of a FePc molecule surrounded by $\mathrm{N}_{2} \mathrm{O}$ species, demonstrating a tip-functionalization event (on the scan line marked by the dashed line). The scan direction is indicated by a blue arrow.

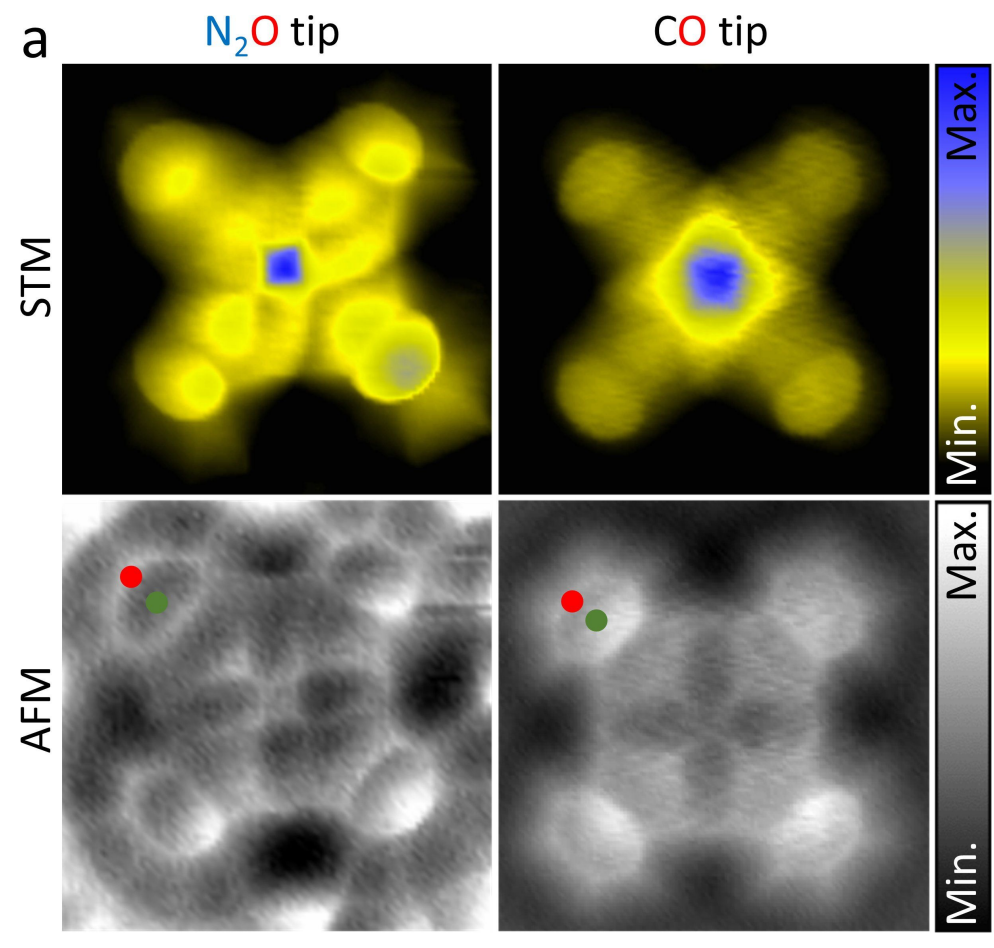

b

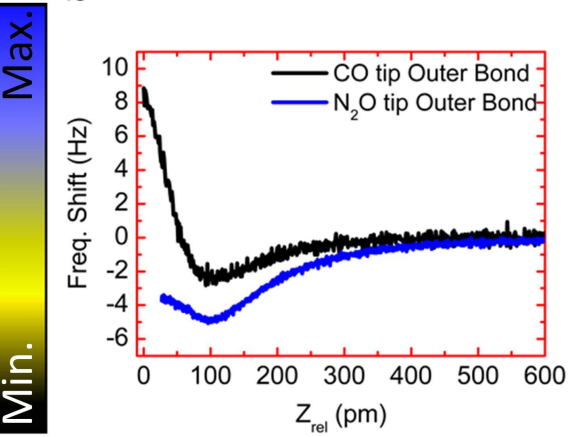

Figure 5: (a) STM and AFM constant-height images of the FePc on $\mathrm{Au}(111)\left(1.7 \times 1.7 \mathrm{~nm}^{2}, V_{\mathrm{b}}=3 \mathrm{mV}\right)$ obtained with two different tip terminations, $\mathrm{N}_{2} \mathrm{O}$ and CO. The STM scale for $\mathrm{N}_{2} \mathrm{O}$ ranges from 0.6 to $43 \mathrm{pA}$ and for CO from 3.8 to $410 \mathrm{pA}$. The AFM gray scale for $\mathrm{N}_{2} \mathrm{O}$ ranges from -23 to $-12 \mathrm{~Hz}$ and for $\mathrm{CO}$ from -12 to $10 \mathrm{~Hz}$. (b) Site-specific $\Delta f$ spectroscopy obtained with $\mathrm{N}_{2} \mathrm{O}$ and $\mathrm{CO}$ tip terminations above the outer $\mathrm{C}-\mathrm{C}$ bonds (red dot) and the centers (green dot) of the peripheral benzene rings of the molecule. 
The observed AFM contrast for both the tips generally corresponds to the FePc backbone structure; it shows the four peripheral benzene rings, the inner pyrrole groups and a signature of the metal atom at the center. In the STM images both tips detect a dominating electron tunneling contribution of the central $\mathrm{Fe}$ molecular orbital at the Fermi level [31] and also the overall shape of the molecule.

The AFM image taken with the $\mathrm{N}_{2} \mathrm{O}$ tip exhibits slightly lower resolution, in comparison to the $\mathrm{CO}$ tip termination, with a strong directionality of the submolecular features within the peripheral benzene rings. The tunneling current image also reveals a significant shadow cast in the same direction as the asymmetric features in AFM. These features are indicative of a general probe asymmetry, consistent with the theoretical calculations, which shows a strongly bent adsorption configuration of the $\mathrm{N}_{2} \mathrm{O}$ molecule on the tip apex.

For a quantitative comparison of the interaction energy of the two tip terminations with $\mathrm{FePc}$, we performed site-specific frequency-shift spectroscopy $\Delta f(z)$ measurements on the outer $\mathrm{C}-\mathrm{C}$ bonds and centers of the peripheral benzene molecules indicated by the red and green dots in Figure 5a. In Figure 5b, the short-range $\Delta f$ curves recorded with $\mathrm{N}_{2} \mathrm{O}$ and $\mathrm{CO}$ tips are shown (after subtracting the background measured on clean $\mathrm{Au}$ [38]). The $\Delta f(z)$ dependence recorded for the $\mathrm{N}_{2} \mathrm{O}$ tips is considerably different from the one obtained with a $\mathrm{CO}$ tip, both qualitatively and quantitatively. The value of the maximum attractive force [39] for the $\mathrm{N}_{2} \mathrm{O}$ tip (Figure $\mathrm{S} 1$, Supporting Information File 1) on both spectroscopy sites (outer $\mathrm{C}-\mathrm{C}$ bond, $F_{\mathrm{N}_{2} \mathrm{O}} \approx-125 \mathrm{pN}$, and hollow site, $\left.F_{\mathrm{N}_{2} \mathrm{O}} \approx-132 \mathrm{pN}\right)$ are significantly higher in comparison to the $\mathrm{CO}$ tip (outer $\mathrm{C}-\mathrm{C}$ bond, $F_{\mathrm{CO}} \approx-30 \mathrm{pN}$, and hollow site, $F_{\mathrm{CO}} \approx-56 \mathrm{pN}$ ). Consequently, the interaction energies (Figure S1, Supporting Information File 1) measured with the $\mathrm{N}_{2} \mathrm{O}$ tip (outer $\mathrm{C}-\mathrm{C}$ bond, $E_{\mathrm{N}_{2} \mathrm{O}} \approx-156 \mathrm{meV}$, and hollow site, $E_{\mathrm{N}_{2} \mathrm{O}} \approx-167 \mathrm{meV}$ ) are substantially greater in comparison to the values measured by the $\mathrm{CO}$ tip (outer $\mathrm{C}-\mathrm{C}$ bond, $E_{\mathrm{CO}} \approx-43 \mathrm{meV}$, and hollow site, $E_{\mathrm{CO}} \approx-75 \mathrm{meV}$ ). This difference can be understood as a result of stronger electrostatic interaction of the molecule with the $\mathrm{N}_{2} \mathrm{O}$ tip, which is consistent with the DFT calculations of the two different tip terminations.

\section{Conclusion}

We have investigated the behavior of $\mathrm{N}_{2} \mathrm{O}$ molecules on the surface of $\mathrm{Au}(111)$ and determined that they adsorb parallel to the surface, forming typical triangular clusters. We were able to readily functionalize a metallic tip with a single $\mathrm{N}_{2} \mathrm{O}$ molecule by picking it up from the $\mathrm{Au}(111)$ substrate and demonstrated that the functionalization of the tip can be achieved even when $\mathrm{N}_{2} \mathrm{O}$ is co-adsorbed on the surface with other species, in this case FePc molecules. We evaluated the performance of the $\mathrm{N}_{2} \mathrm{O}$ tips in submolecular imaging of FePc and site-specific $\Delta f(z)$ spectroscopies. We reproducibly achieved a resolution qualitatively equivalent to the resolution otherwise routinely observed with CO tips, distinguishable by a noticeable asymmetry and higher interaction energies, indicative of a bent adsorption geometry of the $\mathrm{N}_{2} \mathrm{O}$ on the tip and more electrostatic charge relative to CO. These observations were corroborated by DFT calculations.

\section{Methods \\ Experimental}

Experiments were carried out in an ultra-high vacuum STM/ AFM system (Createc) operated at $5 \mathrm{~K}$. The Au(111) sample (Mateck) was cleaned by repeated cycles of sputtering $(1 \mathrm{keV})$ and subsequent annealing to $600{ }^{\circ} \mathrm{C}$. FePc molecules (Sigma Aldrich, evaporation temperature ca. $250{ }^{\circ} \mathrm{C}$ ) were directly evaporated onto a clean $\mathrm{Au}(111)$ surface at room temperature. $\mathrm{N}_{2} \mathrm{O}$ was adsorbed onto the $\mathrm{Au}(111)$ surface at temperatures below $12 \mathrm{~K}$ with exposures of 0.5-1.7 L. AFM measurements were performed with a qPlus sensor (resonance frequency ca. $30 \mathrm{kHz} ; k \approx 1800 \mathrm{~N} / \mathrm{m}$ ), using an oscillation amplitude of $50 \mathrm{pm}$. Prior to functionalization, the Pt tip was repeatedly indented into the $\mathrm{Au}(111)$ substrate several nanometers deep for sharpening and coating with Au. Experimental data were analyzed using WSxM software [40]; all models were visualized using Vesta software [41].

\section{DFT calculations}

We performed density functional theory calculations using the FHI-AIMS code [42] to study the interaction of $\mathrm{N}_{2} \mathrm{O}$ with the $\mathrm{Au}(111)$ surface. We have used a $6 \times 6$ supercell, composed of three $\mathrm{Au}$ layers to represent the $\mathrm{Au}(111)$ surface. Both a single molecule and trimer clusters were initially placed on the surface according to experimental findings. The structural optimization of the slab was carried out, except for the two bottom $\mathrm{Au}$ layers, until the remaining atomic forces and the total energy were found to be below $10^{-2} \mathrm{eV} / \AA$ and $10^{-5} \mathrm{eV}$, respectively. A Monkhorst-Pack grid of $3 \times 3 \times 1$ was used for integration in the Brillouin zone.

DFT calculations were performed at the GGA-PBE level including the Tkatchenko-Scheffler treatment of the van der Waals interactions [43]. The scaled zeroth-order regular approximation [44] was applied to take into account the relativistic effects. The total density and the Hartree potential were calculated to determine the electronic interactions between the surface and the molecules.

AFM images were simulated based on the probe-particle model $[32,45]$, which takes into account van der Waals (vdW) and 
electrostatic interactions between the tip and the sample. The calculations were performed varying the effective charge of the probe particle in order to obtain the best possible agreement between the experimental findings and the simulated AFM images. The lateral stiffness was set to $k=0.25 \mathrm{~N} / \mathrm{m}$. The correlation of the experimental evidence and theory permit us to understand the nature and origin of the chemical contrast.

\section{Supporting Information}

\section{Supporting Information File 1}

Additional computational data.

[https://www.beilstein-journals.org/bjnano/content/

supplementary/2190-4286-10-30-S1.pdf]

\section{Acknowledgements}

This work was supported by the Operational Programme Research, Development and Education financed by European Structural and Investment Funds and the Czech Ministry of Education, Youth and Sports (Project No. SOLID2 1 CZ.02.1.01/0.0/0.0/16_019/0000760). M. S. gratefully acknowledges the grant no. 17-24210Y provided by the Czech grant agency. J. K. gratefully acknowledges the MEYS SAFMAT CZ.02.1.01/0.0/0.0/16_013/0001406, LO1409 and LM2015088 projects. Access to computing and storage facilities owned by parties and projects contributing to the National Grid Infrastructure MetaCentrum provided under the programme "Projects of Large Research, Development, and Innovations Infrastructures" (CESNET LM2015042), is greatly appreciated.

\section{ORCID ${ }^{\circledR}$ iDs}

Pingo Mutombo - https://orcid.org/0000-0002-8175-7587 Jack Hellerstedt - https://orcid.org/0000-0003-2282-8223 Jaromír Kopeček - https://orcid.org/0000-0002-9337-4639 Martin Švec - https://orcid.org/0000-0003-0369-8144

\section{References}

1. Gross, L.; Mohn, F.; Moll, N.; Liljeroth, P.; Meyer, G. Science 2009, 325, 1110-1114. doi:10.1126/science.1176210

2. Gross, L.; Mohn, F.; Moll, N.; Meyer, G.; Ebel, R.; Abdel-Mageed, W. M.; Jaspars, M. Nat. Chem. 2010, 2, 821-825. doi:10.1038/nchem.765

3. Hanssen, K. Ø.; Schuler, B.; Williams, A. J.; Demissie, T. B.; Hansen, E.; Andersen, J. H.; Svenson, J.; Blinov, K.; Repisky, M.; Mohn, F.; Meyer, G.; Svendsen, J.-S.; Ruud, K.; Elyashberg, M.; Gross, L.; Jaspars, M.; Isaksson, J. Angew. Chem., Int. Ed. 2012, 51 12238-12241. doi:10.1002/anie.201203960

4. Schuler, B.; Collazos, S.; Gross, L.; Meyer, G.; Pérez, D.; Guitián, E.; Peña, D. Angew. Chem. 2014, 126, 9150-9152. doi:10.1002/ange.201403707
5. Pavliček, N.; Schuler, B.; Collazos, S.; Moll, N.; Pérez, D.; Guitián, E.; Meyer, G.; Peña, D.; Gross, L. Nat. Chem. 2015, 7, 623-628. doi:10.1038/nchem.2300

6. Gross, L.; Mohn, F.; Moll, N.; Schuler, B.; Criado, A.; Guitian, E.; Pena, D.; Gourdon, A.; Meyer, G. Science 2012, 337, 1326-1329. doi:10.1126/science.1225621

7. Mohn, F.; Gross, L.; Moll, N.; Meyer, G. Nat. Nanotechnol. 2012, 7, 227-231. doi:10.1038/nnano.2012.20

8. Hapala, P.; Švec, M.; Stetsovych, O.; van der Heijden, N. J.; Ondráček, M.; van der Lit, J.; Mutombo, P.; Swart, I.; Jelínek, P. Nat. Commun. 2016, 7, 11560. doi:10.1038/ncomms 11560

9. Albrecht, F.; Repp, J.; Fleischmann, M.; Scheer, M.; Ondráček, M.; Jelínek, P. Phys. Rev. Lett. 2015, 115, 076101. doi:10.1103/physrevlett.115.076101

10. Moreno, C.; Stetsovych, O.; Shimizu, T. K.; Custance, O. Nano Lett. 2015, 15, 2257-2262. doi:10.1021/nl504182w

11. Albrecht, F.; Pavliček, N.; Herranz-Lancho, C.; Ruben, M.; Repp, J. J. Am. Chem. Soc. 2015, 137, 7424-7428. doi:10.1021/jacs.5b03114

12. Albrecht, F.; Bischoff, F.; Auwärter, W.; Barth, J. V.; Repp, J. Nano Lett. 2016, 16, 7703-7709. doi:10.1021/acs.nanolett.6b03769

13. Schuler, B.; Meyer, G.; Peña, D.; Mullins, O. C.; Gross, L. J. Am. Chem. Soc. 2015, 137, 9870-9876. doi:10.1021/jacs.5b04056

14. Schuler, B.; Fatayer, S.; Meyer, G.; Rogel, E.; Moir, M.; Zhang, Y.; Harper, M. R.; Pomerantz, A. E.; Bake, K. D.; Witt, M.; Peña, D.; Kushnerick, J. D.; Mullins, O. C.; Ovalles, C.; van den Berg, F. G. A.; Gross, L. Energy Fuels 2017, 31, 6856-6861. doi:10.1021/acs.energyfuels.7b00805

15. Riss, A.; Paz, A. P.; Wickenburg, S.; Tsai, H.-Z.; De Oteyza, D. G.; Bradley, A. J.; Ugeda, M. M.; Gorman, P.; Jung, H. S.; Crommie, M. F.; Rubio, A.; Fischer, F. R. Nat. Chem. 2016, 8, 678-683. doi:10.1038/nchem.2506

16. de Oteyza, D. G.; Gorman, P.; Chen, Y.-C.; Wickenburg, S.; Riss, A.; Mowbray, D. J.; Etkin, G.; Pedramrazi, Z.; Tsai, H.-Z.; Rubio, A.; Crommie, M. F.; Fischer, F. R. Science 2013, 340, 1434-1437. doi:10.1126/science.1238187

17. Shiotari, A.; Nakae, T.; Iwata, K.; Mori, S.; Okujima, T.; Uno, H.; Sakaguchi, H.; Sugimoto, Y. Nat. Commun. 2017, 8, 16089. doi:10.1038/ncomms16089

18. Rogers, C.; Chen, C.; Pedramrazi, Z.; Omrani, A. A.; Tsai, H.-Z.; Jung, H. S.; Lin, S.; Crommie, M. F.; Fischer, F. R. Angew. Chem., Int. Ed. 2015, 54, 15143-15146. doi:10.1002/anie.201507104

19. Stetsovych, O.; Švec, M.; Vacek, J.; Chocholoušová, J. V.; Jančařík, A.; Rybáček, J.; Kosmider, K.; Stará, I. G.; Jelínek, P.; Starý, I. Nat. Chem. 2017, 9, 213-218. doi:10.1038/nchem.2662

20. de la Torre, B.; Švec, M.; Hapala, P.; Redondo, J.; Krejčí, O.; Lo, R.; Manna, D.; Sarmah, A.; Nachtigallová, D.; Tuček, J.; Błoński, P.; Otyepka, M.; Zbořil, R.; Hobza, P.; Jelínek, P. Nat. Commun. 2018, 9, 2831. doi:10.1038/s41467-018-05163-y

21. Hauptmann, N.; Mohn, F.; Gross, L.; Meyer, G.; Frederiksen, T.; Berndt, R. New J. Phys. 2012, 14, 073032. doi:10.1088/1367-2630/14/7/073032

22. Sweetman, A. M.; Jarvis, S. P.; Sang, H.; Lekkas, I.; Rahe, P.; Wang, Y.; Wang, J.; Champness, N. R.; Kantorovich, L.; Moriarty, P. Nat. Commun. 2014, 5, 3931. doi:10.1038/ncomms4931

23. Shiotari, A.; Odani, T.; Sugimoto, Y. Phys. Rev. Lett. 2018, 121 , 116101. doi:10.1103/physrevlett.121.116101

24. Mohn, F.; Schuler, B.; Gross, L.; Meyer, G. Appl. Phys. Lett. 2013, 102 073109. doi:10.1063/1.4793200 
25. Schuler, B.; Liu, W.; Tkatchenko, A.; Moll, N.; Meyer, G.; Mistry, A.; Fox, D.; Gross, L. Phys. Rev. Lett. 2013, 111, 106103.

doi:10.1103/physrevlett.111.106103

26. Mönig, H.; Hermoso, D. R.; Díaz Arado, O.; Todorović, M.; Timmer, A.; Schüer, S.; Langewisch, G.; Pérez, R.; Fuchs, H. ACS Nano 2016, 10 , 1201-1209. doi:10.1021/acsnano.5b06513

27. Peng, J.; Guo, J.; Hapala, P.; Cao, D.; Ma, R.; Cheng, B.; Xu, L.; Ondráček, M.; Jelínek, P.; Wang, E.; Jiang, Y. Nat. Commun. 2018, 9 , 122. doi:10.1038/s41467-017-02635-5

28. Jelínek, P. J. Phys.: Condens. Matter 2017, 29, 343002. doi:10.1088/1361-648x/aa76c7

29. Wagner, C.; Green, M. F. B.; Leinen, P.; Deilmann, T.; Krüger, P.; Rohlfing, M.; Temirov, R.; Tautz, F. S. Phys. Rev. Lett. 2015, 115, 026101. doi:10.1103/physrevlett.115.026101

30. Chiang, C.-I.; Xu, C.; Han, Z.; Ho, W. Science 2014, 344, 885-888. doi:10.1126/science.1253405

31. de la Torre, B.; Švec, M.; Foti, G.; Krejčí, O.; Hapala, P.; Garcia-Lekue, A.; Frederiksen, T.; Zbořil, R.; Arnau, A.; Vázquez, H.; Jelínek, P. Phys. Rev. Lett. 2017, 119, 166001. doi:10.1103/physrevlett.119.166001

32. Hapala, P.; Kichin, G.; Wagner, C.; Tautz, F. S.; Temirov, R.; Jelínek, P. Phys. Rev. B 2014, 90, 085421. doi:10.1103/physrevb.90.085421

33. Temirov, R.; Soubatch, S.; Neucheva, O.; Lassise, A. C.; Tautz, F. S. New J. Phys. 2008, 10, 053012. doi:10.1088/1367-2630/10/5/053012

34. Wagner, C.; Temirov, R. Prog. Surf. Sci. 2015, 90, 194-222. doi:10.1016/j.progsurf.2015.01.001

35. Kokalj, A.; Matsushima, T. J. Chem. Phys. 2005, 122, 034708. doi:10.1063/1.1829652

36. Murray, J. S.; Politzer, P. Wiley Interdiscip. Rev.: Comput. Mol. Sci. 2011, 1, 153-163. doi:10.1002/wcms.19

37. Hirshfeld, F. L. Theor. Chim. Acta 1977, 44, 129-138. doi:10.1007/bf00549096

38. Lantz, M. A. Science 2001, 291, 2580-2583. doi:10.1126/science.1057824

39. Giessibl, F. J. Appl. Phys. Lett. 2001, 78, 123-125. doi:10.1063/1.1335546

40. Horcas, I.; Fernández, R.; Gómez-Rodríguez, J. M.; Colchero, J.; Gómez-Herrero, J.; Baro, A. M. Rev. Sci. Instrum. 2007, 78, 013705. doi:10.1063/1.2432410

41. Momma, K.; Izumi, F. J. Appl. Crystallogr. 2011, 44, 1272-1276. doi:10.1107/s0021889811038970

42. Blum, V.; Gehrke, R.; Hanke, F.; Havu, P.; Havu, V.; Ren, X.; Reuter, K.; Scheffler, M. Comput. Phys. Commun. 2009, 180, 2175-2196. doi:10.1016/j.cpc.2009.06.022

43. Tkatchenko, A.; Scheffler, M. Phys. Rev. Lett. 2009, 102, 073005. doi:10.1103/physrevlett.102.073005

44. van Lenthe, E.; van Leeuwen, R.; Baerends, E. J.; Snijders, J. G. Int. J. Quantum Chem. 1996, 57, 281-293. doi:10.1002/(sici)1097-461x(1996)57:3<281::aid-qua2>3.0.co;2-u

45. Hapala, P.; Temirov, R.; Tautz, F. S.; Jelínek, P. Phys. Rev. Lett. 2014, 113, 226101. doi:10.1103/physrevlett.113.226101

\section{License and Terms}

This is an Open Access article under the terms of the Creative Commons Attribution License (http://creativecommons.org/licenses/by/4.0). Please note that the reuse, redistribution and reproduction in particular requires that the authors and source are credited.

The license is subject to the Beilstein Journal of Nanotechnology terms and conditions:

(https://www.beilstein-journals.org/bjnano)

The definitive version of this article is the electronic one which can be found at:

doi:10.3762/bjnano.10.30 